\title{
Review Article \\ Role of IL-33 and Its Receptor in T Cell-Mediated Autoimmune Diseases
}

\author{
Qing Zhao and Guangjie Chen
}

Department of Immunology and Microbiology, Shanghai JiaoTong University School of Medicine, Shanghai Institute of Immunology, 280 South Chongqing Road, Shanghai 200025, China

Correspondence should be addressed to Guangjie Chen; guangjie_chen@163.com

Received 27 February 2014; Revised 26 May 2014; Accepted 27 May 2014; Published 16 June 2014

Academic Editor: Oscar Palomares

Copyright (c) 2014 Q. Zhao and G. Chen. This is an open access article distributed under the Creative Commons Attribution License, which permits unrestricted use, distribution, and reproduction in any medium, provided the original work is properly cited.

Interleukin-33 (IL-33) is a new cytokine of interleukin-1 family, whose specific receptor is ST2. IL-33 exerts its functions via its target cells and plays different roles in diseases. ST2 deletion and exclusion of IL-33/ST2 axis are accompanied by enhanced susceptibility to dominantly T cell-mediated organ-specific autoimmune diseases. It has been reported that IL-33/ST2 pathway plays a key role in host defense and immune regulation in inflammatory and infectious diseases. This review focuses on new findings in the roles of IL-33 and ST2 in several kinds of T cell-mediated autoimmune diseases.

\section{Introduction}

Interleukin-33 (IL-33) used to be named as "DVS27" [1]. In 2005 , it was first reported that the gene sequence and structure of IL-33 were similar to those of IL-1 $\beta$ and IL-18 which belong to the IL-1 family [2]. So IL-33 is identified as a new member of the IL-1 superfamily [3]. It can activate mast cells, lymphocytes, and eosinophils to release the Th2-related cytokines $[4,5]$.

Autoimmune diseases result from an abnormal immune response to self-antigens to cause tissue damage. Patients with autoimmune diseases frequently have auto-reactive $\mathrm{T}$ cells and unusual antibodies circulating in their blood that target their own body tissues [6]. Common autoimmune diseases include rheumatoid arthritis (RA), systemic lupus erythematosus (SLE), ankylosing spondylitis, scleroderma, and Sjogren's syndrome. Currently, the exact pathogenesis of autoimmune diseases is still unclear [7]. It is thought that autoimmune disease is caused by different factors including genetic predisposition, environmental factors, and viral infection, which lead to abnormal immune response and loss of immune tolerance in the body.

It has been proven that IL-33 and its receptor play an important role in inflammation, infection, and autoimmune diseases. More recently, IL-33 has been shown to change the symptoms of rheumatoid arthritis, systemic lupus erythematosus, and other autoimmune diseases, which may elicit beneficial or detrimental effects depending on the disease setting $[8,9]$. Therefore, studies on IL-33 may provide a new idea and target for the treatment of autoimmune diseases.

\section{IL-33 \& ST2}

2.1. The Structure of IL-33. In 2003, Baekkevold et al. firstly identified IL-33 from the high endothelial cells; its protein sequence was similar to DVS27 of canine [10]. DVS27 gene was found to encode a nuclear protein that could be involved in inflammatory events. Then in 2005, Schmitz et al. found that IL-33 was related to IL-1 and fibroblast growth factor by using of a computational approach to search sequence databases for proteins [2]. The human IL-33 gene is located on chromosome 9p24.1 and encodes a peptide of 270 amino acids, while this gene maps to chromosome $19 \mathrm{qCl}$ and encodes a peptide of 266 amino acids in mice. IL33 is a $30 \mathrm{kD}$ protein that is evolutionarily conserved in mammals, with $54 \%$ amino acid sequence identity between the human and mouse homologs [11]. IL-33 is a member of the IL-1 superfamily of cytokines, a determination based in part on the molecules $\beta$-trefoil structure, a conserved structure type 
at the carboxyl terminal [12], through which IL-33 exerts its cytokine activity [13]. IL-33 was initially believed to be cleaved by caspase- 1 to release a "mature" $18 \mathrm{kD}$ form corresponding to the C-terminal cytokine domain. However, it soon became clear that the IL-33 protein only contains the cleavage sites of caspase- 3 and caspase- 7 but not the cleavage sites of caspase$1[14,15]$. Recent studies showed that neutrophil-derived caspase and elastase also cleave IL-33 but generate more bioactive cytokines, such as IL- $1 \alpha$, IL-1 $\beta$, and IL-18 [16]. The findings highlight the major differences between the biology of IL-33 and that of IL- $1 \beta[17,18]$.

2.2. IL-33 Receptor. IL-33R is a heterodimer comprised of IL1RL1 (also called ST2) and IL-1 receptor accessory protein (IL1RAcP) [19]. Regarding ST2, its gene was found in 3T3 cell lines derived from BALB/c mice in 1989. The research showed that ST2 was expressed on growth-stimulated BALB/c-3T3 cells but not in resting cells [20]. ST2 gene is located on human chromosome 2 (2q12), its germline sequence is conserved [21]. ST2 is a member of the IL-1 family, which has the Toll/IL-1R domain in the cytoplasmic region. ST2 has 2 major forms: sST2 and ST2L [22]. sST2 is a soluble ST2 which has no transmembrane sequence, so it can be excreted outside the cells, while ST2L is the transmembrane ST2 for having transmembrane sequence; both of them are produced from the IL-1RL1 gene as a result of alternative splicing under the control of two distinct promoters [23, 24]. The transmembrane-form ST2L is considered to be a functional component of IL-33R, whereas sST2 is regarded as a decoy receptor for IL-33, like soluble IL-1R for IL- $1 \alpha$ and IL-1 $\beta$ [25]. Compared with sST2, the structure of ST2L is more similar to IL-1R. What is more, ST2V and ST2LV are two splice variants of ST2. Loss of the third immunoglobulin motif and alternatives splicing in the C-terminal portion of ST2, resulting in a unique hydrophobic tail, produces ST2V, whereas alternative splicing, leading to deletion of the transmembrane domain of ST2L, produces ST2LV [26].

2.3. Physiological Functions. IL33 is a dual-function protein that acts as both a cytokine and a nuclear factor. In some mice study, it is constitutively expressed by the epithelial and endothelial cells of many organs [27], and it is also expressed by some innate immune cells such as dendritic cells and macrophages $[28,29]$. IL-33 can increase the expression of IL- 5 and IL-13 in Th2 cells [30, 31], but IL-33 cannot improve the expression level of IL-4 [32]. It implies that IL-33 is not necessary for the differentiation of Th 2 cells. Native CD 4 and Th1 cells do not express IL-33R, culture of resting Th2 cells in medium containing IL-33 combined with IL-2, IL-7, or TSLP, and cause upregulation of IL-33R expression [32].

IL-33 is a ligand that binds to a high affinity receptor family member ST2 [33]. ST2 expresses on the surface of both mouse and human mast cells [34]. Without causing degranulation, IL-33 can induce mast cells to produce chemokines and cytokines. But some other studies showed that IL-33 could promote IgE mediated cytokine production and cause degranulation of mast cells in mice [35]. IL-33 can also induce basophils to produce Th2-type cytokines and chemokines at the same time and then increases the expression of cell adhesion molecules and CD11b on basophils both in human and mice $[36,37]$.

It was reported that Th2 lymphocytes, mast cells, macrophages, dendritic cells, CD8 T cells, and B cells and some granulocytes such as basophils and eosinophils are possible to express membrane-type ST2 molecules [34, 38, 39]. IL-33 could induce the production of many cytokines such as IL-5, IL-13, TNF- $\alpha$, IFN- $\gamma$, and IL- 2 when binding with ST2 receptors on the surface of those cells [40, 41]. Therefore, IL-33 and ST2 play an important role in allergic diseases and various mucosal immune responses, suggesting the involvement of the IL-33/ST2 pathway in the pathogenesis of a large number of diseases, especially in the responses based on the Th2 type $[5,37]$.

Recently, group 2 ILCs, which include IL-5- and IL13-producing ILCs such as natural helper cells (NHCs), nuocytes, and innate helper type 2 (Ih2) cells, are reported to be critically dependent on the epithelial cell-derived cytokines IL-33 and IL-25 and have been shown to promote anti-helminth immunity and regulate inflammation and/or epithelial repair in the lung [42]. And it is also found that IL-33, which is released from necrotic cells, is necessary for potent CD8+ T cell (CTL) responses to replicating prototypic RNA and DNA viruses in mice [39].

Accumulating evidence suggests a crucial role of IL33/ST2 in inducing and modifying host immune responses against a variety of pathogens including parasites, bacteria, viruses, and fungi as well as sterile insults of both endogenous and exogenous source [43].

DCs are the major antigen-presenting cells and play a pivotal role in immune responses. DCs respond directly to IL-33 through ST2 [44]. DCs not only respond to IL-33 but also produce IL-33 in allergic condition [45]. The interaction between IL-33 and DCs may represent a new pathway to initiate Th2-type immune responses.

In addition, ST2 blocking antibody or IgG2-ST2 fusion proteins can activate Th1 cells to enhance Th1 cell responses [46], while they inhibit the allergic airway inflammation caused by the Th2 cells [47].

2.4. IL-33/ST2 Signaling Pathway. Kakkar's study has shown that IL-33/ST2 signaling pathway was involved in T cellmediated immune response and was a potential medium for a variety of inflammatory diseases. IL-33 may function as a modulator of NF- $\kappa \mathrm{B}$ and canonical Toll-like receptor/IL-1 receptor signaling [48].

As shown in Figure 1, IL-33 can transfer extracellular information by binding with the ST2 receptor complex when serving as a conventional cytokine [43]. Furthermore, IL33 can act as an intracellular nuclear factor which inhibits the transcription. Nuclear IL-33 is thought to be involved in transcriptional repression by binding to the $\mathrm{H} 2 \mathrm{~A}-\mathrm{H} 2 \mathrm{~B}$ acidic pocket of nucleosomes and regulating chromatin compaction by promoting nucleosome-nucleosome interactions. However, the specific transcriptional targets or the biological effects of nuclear IL-33 are unclear at present [49]. Based 
on the previous researches, it has been recognized that IL33 signaling pathways are different from the typical Th2 cytokines mediated pathway.

IL-33 binds with the receptor complex containing ST2 and IL-1RAcp and acts through the Toll/IL-1 receptor domain of IL-1 receptor accessory protein (IL-1RAcp), which is shared by other IL-1 family members such as IL-1R and IL$18 \mathrm{R}$, to transduce the IL-33/ST2 signal $[50,51]$. This causes the recruitment of MyD88 (myeloid differentiation primary response gene 88), IRAK (interleukin-1 receptor-associated kinase 1), and IRAK4 (interleukin-1 receptor-associated kinase 4) by the intracellular TIR domain of IL-1RAcP [52]. Then the complex activates the transcription factor NF- $\kappa \mathrm{B}$ and AP-1 through mitogen activated protein kinases (MAPK) or TNF receptor associated factor 6 (TRAF6), finally causing inflammatory responses [2].

Single Immunoglobulin IL-1 Receptor-Related molecule (SIGIRR) which is also named as the Toll-Interleukin-1 Receptor 8(TIR8) belongs to the IL-1 receptor family. It has been reported to be a negative regulator in IL-1R and Toll-like receptor-mediated immune responses [72]. SIGIRR could be formed into a complex together with the ST2 on the membrane. Then the new combined complex could inhibit IL-33/ST2 signaling pathway [73, 74] (Figure 1). Some studies showed that the dendritic cells of SIGIRR gene deficient mice performed higher immunoreactivity after stimulation with IL-1, IL-18, and TLR agonists [75]. In addition, the level of Th2 cytokines was increased in Th2 cells after IL-33 stimulation in SIGIRR-deficient mice [74].

\section{IL-33/ST2 Axis in Autoimmune Diseases}

IL-33 exerts its functions via its target cells and plays different roles in diseases. IL-33 has been implicated in a wide range of immune-mediated diseases, including allergic, cardiovascular, and autoimmune conditions, which, depending on the disease setting, may elicit beneficial or detrimental effects [43]. ST2 deletion and exclusion of IL-33/ST2 axis are accompanied by enhanced susceptibility to dominantly $\mathrm{T}$ cell-mediated organ-specific autoimmune diseases [76]. Table 1 lists the major findings in the context of IL-33 and ST2 in autoimmune diseases.

3.1. IL-33/ST2 Axis in Rheumatoid Arthritis. Rheumatoid arthritis (RA) is a chronic systemic inflammatory disease characterized by the immune cell mediated destruction of the joint architecture [77]. Elevated levels of proinflammatory cytokines are a key feature in patients with RA.

The majority of IL-1 family members currently known are proinflammatory cytokines in RA [78]. It has been shown that IL-33 was highly expressed in the synovium of RA patients by in situ hybridization experiments [53]. And IL-33 expression was increased in inflammation parts of collagen-induced arthritis model in mice. Meanwhile, local high expression of IL-33 is the pathological basis of joint inflammation and bone destruction [79]. The observations suggested that inhibition of IL-33R may have the same role in the treatment of rheumatoid arthritis which is similar to IL-1 suppressor pathway [80]. What's more, treatment of anti-TNF- $\alpha$ antibody (infliximab) dramatically decreased the level of IL-33 in clinical therapy of RA patients, which is more effective than treatment with methotrexate alone. Therefore, the measurement of IL-33 production in serum could be a distinct marker for monitoring the efficacy of RA treatment.

In the synovium of RA patients, IL-33 was mainly expressed in vascular endothelial cells, fibroblasts, and some CD68+ mononuclear inflammatory cells $[46,81]$, while the synovial fibroblasts had little or even no expression of IL33 [82]. In addition, many studies showed that IL-33 levels were significantly increased in synovial fluid and serum of RA patients compared with healthy controls, suggesting that high levels of IL-33 may be associated with the pathogenesis of RA $[54,83]$. Another study pointed out that there is no correlation between the IL-33 concentration and disease activity of RA, but it was positively correlated with autoantibody levels, suggesting that IL-33 may be related with autoantibodies in RA [53].

Xu's group found that with the administration of IL-33 in collagen-induced arthritis, the aggravated symptoms of RA appeared in wild type mice, and proinflammatory cytokines and anticollagen antibodies were elevated too. In contrast, these phenomena were not found in ST2 genetic deficient mice. Notably, when transferring mast cells to the ST2 genetic deficient mice, the above situation was reversed, both the symptoms and expression of proinflammatory cytokines were the same as those of the wild type. This implied that IL33 exacerbates antigen-induced arthritis by acting on mast cells [82]. Verri et al. found the aggregation of neutrophil in the arthritis model of mice during which accompany the increased expression of IL-33 mRNA and IL-33R, whereas IL-33R deficient mice were less susceptible to arthritis invasion. More reports demonstrated that inhibiting the IL$33 \mathrm{R}$ expression of neutrophil could prevent the migration of neutrophil induced by IL-33, and which might be the important mechanism of the effect of anti-TNF- $\alpha$ on RA. Administration of sST2 which could neutralize IL-33 on collagen-induced arthritis in rats can reduce arthritis significantly, including reducing the clinical symptoms, synovial hyperplasia, and joint erosion. The mechanism is that sST2 can reduce the level of IL- 6 , IL-12, and TNF- $\alpha$ by neutralizing IL-33, thereby ameliorating the pathological symptoms in antigen-induced arthritis of rats in vivo [84]. In anti-ST2treated mice, draining lymph node cells produced less IL17 compared with the control group indicating that IL-33 is able to enhance Th17 responses. Recently, a new study [55] reported that endogenous IL-33 was not necessary for the development of joint inflammation in autoantibody-induced arthritis of IL-33-deficient mice. But it was also found that ST2-deficient mice had reduced arthritis severity in that study. This research indicates an IL-33-independent effect of ST2.

Taken together, these data imply that the IL-33/ST2 pathway plays a critical role in the pathogenesis of rheumatoid arthritis. 


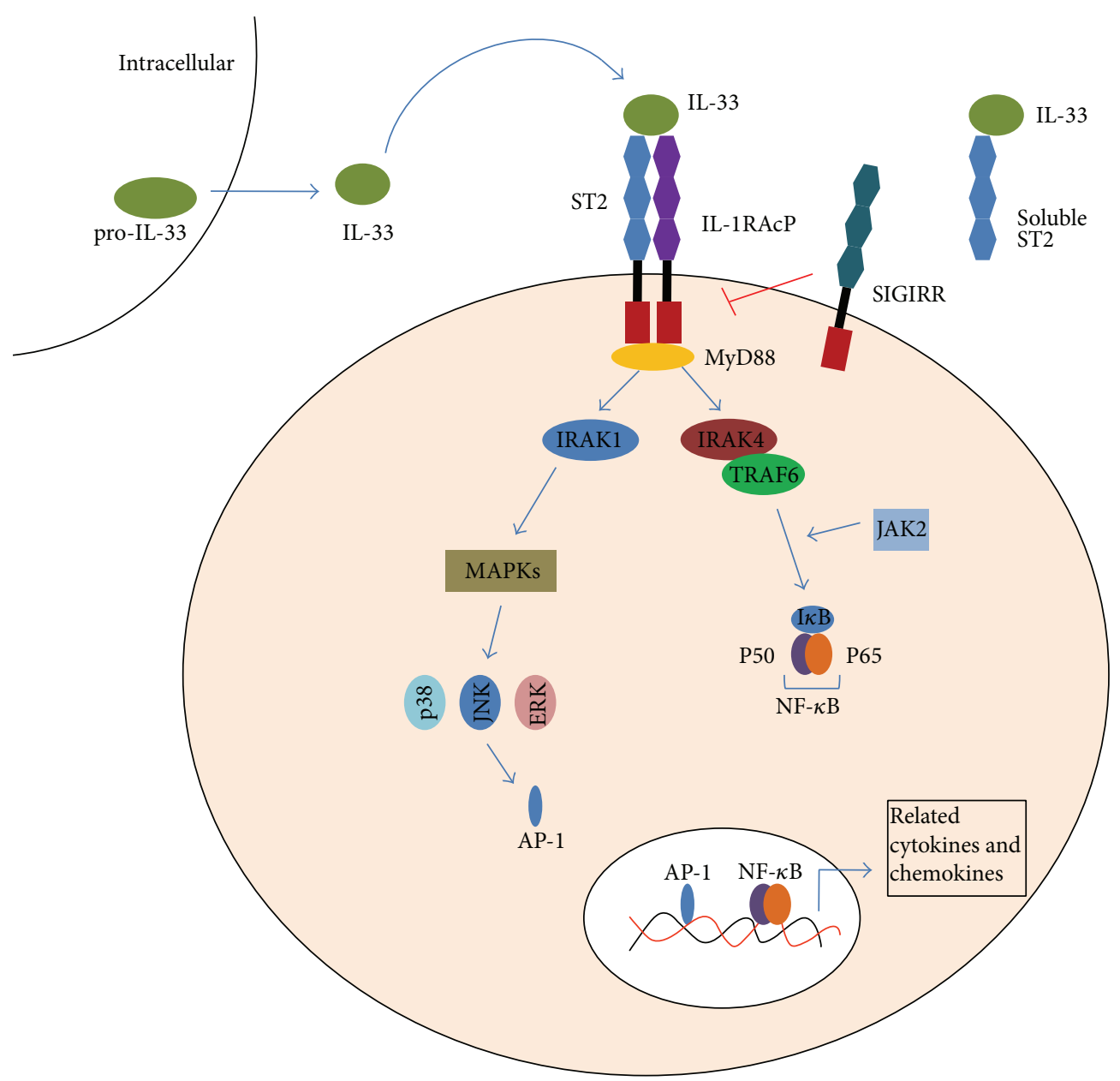

FIGURE 1: IL-33/ST2 signaling pathway. IL-33 is the ligand for ST2. It activates the ST2L/IL-1RAcP dimers or is neutralized by binding to sST2. The interaction of IL-33 with ST2 leads to the recruitment of the myeloid differentiation primary-response protein 88 (MyD88), IL1R-associated kinase 1 (IRAK1) and IRAK4, which result in the activation of at least two independent pathways: the transcription factor nuclear factor- $\kappa \mathrm{B}(\mathrm{NF}-\kappa \mathrm{B})$ and the mitogen-activated protein kinase (MAPK) pathway, ultimately induce related gene expression. It induces the production of IL-2, IL-5, IL-13, TNF- $\alpha$, and IFN- $\gamma$. IL-33 can also combine with single Ig IL-1R-related molecule (SIGIRR), which seems as an inhibitor of IL-33/ST2 pathway.

TABLE 1: Dysregulated expression of IL-33 and ST2 in some autoimmune diseases.

\begin{tabular}{ll}
\hline Disease & Major findings \\
\hline \multirow{3}{*}{ RA } & Levels of IL-33 and ST2 are increased in serum, synovial fluid, and synovium. \\
& Level of serum IL-33 correlates with RA-related autoantibodies but not RA severity. \\
& IL-33 enhances Th17 response. \\
\hline \multirow{4}{*}{ IL-33/ST2 signal pathway activates NF- $\kappa$ B, STAT1, and STAT6, thereby contributing to demyelination. } \\
Level of IL-33 is increased in the spinal cord of MS patients. \\
Levels of IL-33 and ST2 are increased in the spinal cord of EAE. \\
Contradictory functions of IL-33 in EAE: IL-33 attenuates EAE but IL-33 administration aggravates EAE. \\
\hline \multirow{3}{*}{ SLE } & Levels of IL-33 and ST2 are increased in serum in SLE patients. \\
& IL-33 correlates with ESR and CRP, but not the kidney damage disease activity in SLE patients. \\
& Serum ST2 correlates with severity of SLE. \\
\hline & Levels of IL-33 and ST2 are increased in serum. \\
[BD & Level of IL-33 is increased in mucosa. \\
& IL-33 correlates with UC activity and IBD severity. \\
& IL-33 induces IL-5, IL-6, and IL-17 production. \\
\hline
\end{tabular}


3.2. IL-33/ST2 Axis in Multiple Sclerosis. Brain and spinal cord are the organs which have the highest expression of IL-33 [2]. Astrocytes are the nonhematopoietic epithelial cells in the central nervous system (CNS), and they could express IL-33 receptor 2 subunit ST2 and IL-1RAcP $[85,86]$. Therefore, CNS glial cells, particularly astrocytes, can possibly be activated by IL-33. IL-33 can induce proliferation of microglia and also improve the expression of proinflammatory cytokines IL-1 $\beta$ and TNF- $\alpha$, while increasing the expression of antiinflammatory factor IL-10 at the same time. Microglial cells secrete various cytokines and chemokines, which are a major regulator of the central nervous system [87].

Multiple sclerosis is an inflammatory disease of the CNS, characterized by inflammatory lesions, demyelination, and axonal loss. Based on the findings between IL-33 and CNS cells, many studies have shown that IL-33 played an important role in MS [88]. MS lesions are restricted to the central nervous system and are characterized by infiltration of lymphocytes, macrophages, and dendritic cells [89]. These cells can cause inflammatory cytokine gene expression and the formation of toxic protein to promote damage in CNS. IL-33/ST2 signal pathway could activate the gene of NF- $\kappa$ B, STAT1, and STAT6, thereby contributing to demyelination $[56,57]$. In addition, the mast cells of MS patients are an important kind of inflammatory cells. IL-33 can activate the mast cells in CNS by degranulation and inducing the production of a number of proinflammatory cytokines [4]. Christophi et al. found that, compared with normal subjects, the expression mRNA and protein level of IL-33 are remarkably higher in plasma, CNS lesions, and normal white matter (NAWM) of MS patients [58]. It was also found that NF- $\kappa \mathrm{B}$ expression level was significantly increased in the peripheral blood mononuclear cells and macrophages in vitro from MS patients [58]. Furthermore, treatment of IFN$\beta$ can simultaneously reduce the expression of NF- $\kappa \mathrm{B}$ and IL-33 both in vivo and in vitro [90]. The viral or bacterial components such as lipopolysaccharide and flagellin owe the ability to induce NF- $\kappa \mathrm{B}$ expression to the Toll-like receptor3 and Toll-like receptor5 [91], and viral infections can induce astrocytes secreting IL-33 [92]. Therefore, IL-33 plays the regulatory role by feedback mechanism in the pathogenesis of MS [59].

Experimental autoimmune encephalomyelitis (EAE) is an inflammatory demyelinating disease of the central nervous system that serves as a classic animal model for MS. Recent studies have found that the level of IL-33 is higher in the CNS of EAE mice compared with the normal controls [60]. The significantly raised level of IL-33 from endothelial cells and astrocytes exert vital regulating action in CNS. By increasing of IL-33, the activity of astrocytes was affected subsequently, ultimately resulting in the proliferation of microglia and secretion of cytokines and chemokines [87]. During the inductive phase of EAE, IL-33 administration aggravates the disease, while anti-IL-33 antibody significantly inhibits the onset and severity of EAE by reducing MOG35-55 specific stimulated production of IFN- $\gamma$ and IL-17 [61].

However, some completely opposite findings have been reported. Jiang's group demonstrated that IL-33 administration after EAE onset is protective against the disease. The effect of IL-33 is likely endogenous as ST2 $2^{-/-}$mice developed exacerbated disease following EAE induction. Furthermore, the beneficial effect of IL-33 is accompanied by a switch from the predominant pathogenic Th17 and Th1 response to the protective Th2-type immune activity. Moreover, IL-33 treatment also resulted in an increase in regulatory $\mathrm{T}$ cell (Treg) frequency and the polarization of alternative macrophages, which has been previously demonstrated to be associated with a favorable outcome of EAE [62]. Another study also showed that BALB/c mice developed highly inflammatory $\mathrm{T}$ helper cells by targeting ST2 gene. These cells were able to enter CNS, produced inflammatory cytokines, and disturbed blood brain barrier, then enabled influx of other immune cells in CNS and caused EAE in the absence of ST2 molecule in contrast to WT mice [63].

Although the reason for the difference in the above findings is still not known and the exact pathophysiological function of the IL-33/ST2 axis in MS requires further investigation, it's believed that IL-33/ST2 axis plays some important role in MS development. It is possible that IL-33 may become a potential biomarker for MS in the future, as well as the target of MS treatment.

3.3. IL-33/ST2 Axis in Systemic Lupus Erythematosus. Systemic lupus erythematosus (SLE) is a multisystemic autoimmune disease, characterized by hyper gamma globulinemia and a plethora of autoantibodies as well as proinflammatory cytokines. Both Th1 and Th2 responses have been implicated in the pathogenesis of lupus [64].

The studies have pointed out that the level of IL-33 is abnormal in the serum of SLE patients, suggesting that IL-33 may be involved in the pathogenesis of SLE [65]. The studies also analyzed the relationship between IL-33 and the kidney damage in SLE as well as disease activity.

Mok's group demonstrated the sST2 level was higher in SLE patients with active disease including renal or nonrenal manifestations compared with those with lesser disease activity and normal controls. In view of the significant correlation between serum sST2 level and parameters of disease activity, its responsiveness to change in the levels of disease activity when monitored longitudinally and its lack of association with age, sex, and impaired renal function, sST2 may serve as a potential surrogate marker for disease activity in SLE [66]. In Yang's study, it was found that the level of IL-33 in serum, which was not influenced by gender or age, were significantly increased in patients with SLE, compared with healthy people [93].

In patients with SLE, most clinical and laboratory characteristics did not correlate with serum IL-33 levels, with exceptions of thrombocytopenia, erythrocytopenia, anti-SSB antibody, ESR, CRP, and IgA. Patients with SLE showed close correlation of IL-33 with ESR, CRP, and IgA [93]. Moreover, IL-33 may exert biologic effects on erythrocytes and platelets or their precursors in SLE. As it is known to all, ESR and CRP are diagnostic indicators which represent the SLE patients being in the acute inflammation phase. The results suggest that IL-33 may be involved in the acute inflammation phase of SLE, but it was not associated with course of the disease. 
Sigrr acts as a novel SLE susceptibility gene in mice; lack of Sigrr enhanced the activation and proliferation of B cells, including the production of autoantibodies against multiple nuclear lupus autoantigens [94].

3.4. IL-33/ST2 Axis in Inflammatory Bowel Disease. Inflammatory bowel disease (IBD) is chronic recurrent disease, including ulcerative colitis (UC) and Crohn's disease (CD). The etiology and pathogenesis are not clear, but it is known that inflammatory response caused by abnormal intestinal mucosal immune system plays an important role in the pathogenesis of IBD.

In recent years, scientific interest in the significance of the IL-33/ST2 system in IBD physiopathology has grown [95]. In 2010, five different research groups consistently described the dysregulation of IL-33 in patients with inflammatory bowel disease (IBD) [67-70,96]. And the IL-33 level correlates with UC activity. The results showed that a specific increase of mucosal IL-33 in active UC localized primarily to intestinal epithelial cells (IEC) and colonic inflammatory infiltrates. Infliximab (anti-TNF) treatment of UC decreased circulating IL-33 and increased sST2 level, whereas stimulation of HT29 IEC by TNF in vitro results in increase of IL-33 and sST2 [69]. IL-33 was increased and correlated with disease severity, further induced IL-5, IL-6, and IL-17 production from mesenteric lymph node (MLN) cells, and displayed a similar pattern of mucosal cell production as IBD patients [71].

Animal models of IBD were subsequently utilized in other studies in order to mechanistically determine the precise role of IL-33 in chronic intestinal inflammation. It is found that IL-33/ST2 pathway might possess dichotomous functions. One is to enhance inflammatory responses, the other is to promote epithelial integrity. In two experimental models of IBD, genetic ablation of ST2 significantly improved signs of colitis, while a sustained epithelial expression of the cyto-protective factor connexin-43 was observed in DSStreated ST2-deficient mice. Absence of ST2-mediated signaling in nonhematopoietic cells protects against Dextran sulfate sodium (DSS) induced colitis. In addition, IL-33 treatment impaired epithelial barrier permeability in vitro and in vivo, whereas absence of ST2 enhanced wound healing response upon acute mechanical injury in the colon [97]. It is also reported that IL-33 reduced disease severity by modulating Th1 inflammation and induced a shift to Th2-associated cytokine production in this model [98].

According to the results of a new survey, IL-33 and ST2 genes are early induced in the colonic tissue during DSSinduced colitis. Furthermore, IL-33 exacerbates acute colitis in association with the induction of proinflammatory and angiogenic cytokine as well as chemokine production in a ST2 and IL-4 dependent manner [99].

Recent data which were obtained in an Italian cohort of adult and pediatric UC and CD patients demonstrated that specific IL-33 and ST2 gene polymorphisms confer an increased risk of developing IBD (both UC and CD), suggesting the involvement of the IL-33/ST2 axis in the onset of chronic intestinal inflammation [100]. Garlanda et al. reported that TIR8 represents a negative pathway regulation of the IL-1 receptor/TLR system, expressed in epithelial cells and DC, crucial for tuning inflammation in the gastrointestinal tract [75].

All these findings may lead to exciting potential therapeutic strategies for IBD patients.

\section{Conclusion}

As a kind of proinflammatory cytokines, IL-33 cause the immune pathological damage in some tissues [101]. It plays the important role in chronic inflammatory and autoimmune diseases. It has been proven that IL-33/ST2 signal transduction pathways are involved in various pathological processes. IL-33 and its receptor ST2 are the potential targets for the treatment of allergic and autoimmune inflammatory diseases. However, their exact roles in these diseases still remained poorly understood.

Therefore, the needs for more researches in molecular biology, genetics, immunology, and other related disciplines are urgent. And further study of IL-33 and ST2 structure, function, and signal transduction pathways involved in autoimmune diseases is required. These will provide new ideas for the treatment of autoimmune diseases and other diseases.

\section{List of Abbreviations}

$\begin{array}{ll}\text { CD: } & \text { Crohn's disease } \\ \text { CNS: } & \text { Central Nervous System } \\ \text { CRP: } & \text { C-Reactive Protein } \\ \text { EAE: } & \text { Experimental Autoimmune } \\ & \text { Encephalomyelitis } \\ \text { ESR: } & \text { Erythrocyte Sedimentation Rate } \\ \text { IBD: } & \text { Inflammatory Bowel Disease } \\ \text { IEC: } & \text { Intestinal Epithelial Cells } \\ \text { IL-1RAcP: } & \text { IL-1 Receptor Accessory Protein } \\ \text { IRAK: } & \text { Interleukin-1 Receptor-Associated Kinase } \\ \text { MAPK: } & \text { Mitogen Activated Protein Kinases } \\ \text { MLN: } & \text { Mesenteric Lymph Node } \\ \text { MS: } & \text { Multiple Sclerosis } \\ \text { MyD88: } & \text { Myeloid Differentiation Primary Response } \\ & \text { Gene 88 } \\ \text { RA: } & \text { Rheumatoid Arthritis } \\ \text { SIGIRR: } & \text { Single Immunoglobulin IL-1 } \\ & \text { Receptor-Related Molecule } \\ \text { SLE: } & \text { Systemic Lupus Erythematosus } \\ \text { TRAF6: } & \text { TNF Receptor Associated Factor } \\ \text { UC: } & \text { Ulcerative Colitis. } \\ & \end{array}$

\section{Conflict of Interests}

The authors declare that there is no conflict of interests regarding the publication of this paper. 


\section{Acknowledgments}

This work was supported by Grants from National Nature Science Foundation of China (81373208), Shanghai Commission of Science and Technology (11JC1411602), Shanghai Municipal Education Commission (12ZZ103), and Shanghai Board of Health Foundation (2011177).

\section{References}

[1] H. Onda, H. Kasuya, K. Takakura et al., "Identification of genes differentially expressed in canine vasospastic cerebral arteries after subarachnoid hemorrhage," Journal of Cerebral Blood Flow and Metabolism, vol. 19, no. 11, pp. 1279-1288, 1999.

[2] J. Schmitz, A. Owyang, E. Oldham et al., "IL-33, an interleukin1-like cytokine that signals via the IL-1 receptor-related protein ST2 and induces T helper type 2-associated cytokines," Immunity, vol. 23, no. 5, pp. 479-490, 2005.

[3] W. B. Cherry, J. Yoon, K. R. Bartemes, K. Iijima, and H. Kita, "A novel IL-1 family cytokine, IL-33, potently activates human eosinophils," Journal of Allergy and Clinical Immunology, vol. 121, no. 6, pp. 1484-1490, 2008.

[4] T. C. Theoharides, K.-D. Alysandratos, A. Angelidou et al., "Mast cells and inflammation," Biochimica et Biophysica ActaMolecular Basis of Disease, vol. 1822, no. 1, pp. 21-33, 2012.

[5] J. Louten, A. L. Rankin, Y. Li et al., "Endogenous IL-33 enhances Th2 cytokine production and T-cell responses during allergic airway inflammation," International Immunology, vol. 23, no. 5, pp. $307-315,2011$.

[6] G. Lettre and J. D. Rioux, "Autoimmune diseases: insights from genome-wide association studies," Human Molecular Genetics, vol. 17, no. 2, pp. R116-R121, 2008.

[7] Z. Rosman, Y. Shoenfeld, and G. Zandman-Goddard, "Biologic therapy for autoimmune diseases: an update," BMC Medicine, vol. 11, no. 1, article 88, 2013.

[8] R. Kakkar, H. Hei, S. Dobner, and R. T. Lee, "Interleukin 33 as a mechanically responsive cytokine secreted by living cells," Journal of Biological Chemistry, vol. 287, no. 9, pp. 6941-6948, 2012.

[9] J. Seltmann, T. Werfel, and M. Wittmann, "Evidence for a regulatory loop between IFN- $\gamma$ and IL-33 in skin inflammation," Experimental Dermatology, vol. 22, no. 2, pp. 102-107, 2013.

[10] E. S. Baekkevold, M. Roussigné, T. Yamanaka et al., "Molecular characterization of NF-HEV, a nuclear factor preferentially expressed in human high endothelial venules," American Journal of Pathology, vol. 163, no. 1, pp. 69-79, 2003.

[11] G. Palmer and C. Gabay, "Interleukin-33 biology with potential insights into human diseases," Nature Reviews Rheumatology, vol. 7, no. 6, pp. 321-329, 2011.

[12] J. Chapuis, D. Hot, F. Hansmannel et al., "Transcriptomic and genetic studies identify IL-33 as a candidate gene for Alzheimer's disease," Molecular Psychiatry, vol. 14, no. 11, pp. 1004-1016, 2009.

[13] P. Han, W.-L. Mi, and Y.-Q. Wang, "Research progress on interleukin-33 and its roles in the central nervous system," Neuroscience Bulletin, vol. 27, no. 5, pp. 351-357, 2011.

[14] C. Cayrol and J.-P. Girard, "The IL-1-like cytokine IL-33 is inactivated after maturation by caspase-1," Proceedings of the National Academy of Sciences of the United States of America, vol. 106, no. 22, pp. 9021-9026, 2009.
[15] A. U. Lüthi, S. P. Cullen, E. A. McNeela et al., "Suppression of Interleukin-33 Bioactivity through Proteolysis by Apoptotic Caspases," Immunity, vol. 31, no. 1, pp. 84-98, 2009.

[16] E. Sundlisæter, R. J. Edelmann, J. Hol et al., "The alarmin IL-33 is a notch target in quiescent endothelial cells," American Journal of Pathology, vol. 181, no. 3, pp. 1099-1111, 2012.

[17] T. Ohno, K. Oboki, N. Kajiwara et al., "Caspase-1, caspase-8, and calpain are dispensable for IL-33 release by macrophages," Journal of Immunology, vol. 183, no. 12, pp. 7890-7897, 2009.

[18] S. Ali, D. Q. Nguyen, W. Falk, and M. U. Martin, "Caspase 3 inactivates biologically active full length interleukin-33 as a classical cytokine but does not prohibit nuclear translocation," Biochemical and Biophysical Research Communications, vol. 391, no. 3, pp. 1512-1516, 2010.

[19] S. Nakae, H. Morita, T. Ohno, K. Arae, K. Matsumoto, and H. Saito, "Role of Interleukin-33 in Innate-Type immune cells in allergy," Allergology International, vol. 62, no. 1, pp. 13-20, 2013.

[20] S. Tominaga, "A putative protein of a growth specific cDNA from BALB/c-3T3 cells is highly similar to the extracellular portion of mouse interleukin 1 receptor," FEBS Letters, vol. 258, no. 2, pp. 301-304, 1989.

[21] I. G. Luzina, E. M. Pickering, P. Kopach et al., "Full-length IL33 promotes inflammation but not Th2 response in vivo in an ST2-independent fashion," Journal of Immunology, vol. 189, no. 1, pp. 403-410, 2012.

[22] J. Lin, L. Zhang, G. Zhao et al., "A novel interleukin 33/ST2 signaling regulates inflammatory response in human corneal epithelium," PLoS ONE, vol. 8, no. 4, Article ID e60963, 2013.

[23] K. Oboki, T. Ohno, N. Kajiwara, H. Saito, and S. Nakae, "IL-33 and IL-33 receptors in host defense and diseases," Allergology International, vol. 59, no. 2, pp. 143-160, 2010.

[24] D. E. Smith, "IL-33: a tissue derived cytokine pathway involved in allergic inflammation and asthma," Clinical and Experimental Allergy, vol. 40, no. 2, pp. 200-208, 2010.

[25] T. Ohno, H. Morita, K. Arae, K. Matsumoto, and S. Nakae, "Interleukin-33 in allergy," Allergy, vol. 67, no. 10, pp. 1203-1214, 2012.

[26] S. Tominaga, "A putative protein of a growth specific cDNA from BALB/c-3T3 cells is highly similar to the extracellular portion of mouse interleukin 1 receptor," FEBS Letters, vol. 258, no. 2, pp. 301-304, 1989.

[27] A. S. Mirchandani, R. J. Salmond, and F. Y. Liew, "Interleukin33 and the function of innate lymphoid cells," Trends in Immunology, vol. 33, no. 8, pp. 389-396, 2012.

[28] T. Ohno, K. Oboki, N. Kajiwara et al., "Caspase-1, caspase-8, and calpain are dispensable for IL-33 release by macrophages," Journal of Immunology, vol. 183, no. 12, pp. 7890-7897, 2009.

[29] D. Talabot-Ayer, N. Calo, S. Vigne, C. Lamacchia, C. Gabay, and G. Palmer, "The mouse interleukin (II)33 gene is expressed in a cell type- and stimulusdependent manner from two alternative promoters," Journal of Leukocyte Biology, vol. 91, no. 1, pp. 119125, 2012

[30] Y. Kondo, T. Yoshimoto, K. Yasuda et al., "Administration of IL-33 induces airway hyperresponsiveness and goblet cell hyperplasia in the lungs in the absence of adaptive immune system," International Immunology, vol. 20, no. 6, pp. 791-800, 2008.

[31] M. Kurowska-Stolarska, P. Kewin, G. Murphy et al., "IL-33 induces antigen-specific IL-5+ T cells and promotes allergicinduced airway inflammation independent of IL-4," Journal of Immunology, vol. 181, no. 7, pp. 4780-4790, 2008. 
[32] L. Y. Guo, G. Wei, J. F. Zhu et al., "IL-1 family members and STAT activators induce cytokine production by Th2, Th17, and Th1 cells," Proceedings of the National Academy of Sciences of the United States of America, vol. 106, no. 32, pp. 13463-13468, 2009.

[33] T. Stampalija, T. Chaiworapongsa, R. Romero et al., "Soluble ST2, a modulator of the inflammatory response, in preterm and term labor," Journal of Maternal-Fetal and Neonatal Medicine, vol. 27, no. 2, pp. 111-121, 2014.

[34] Y. Baba, K. Maeda, T. Yashiro et al., "GATA2 is a critical transactivator for the human IL1RL1/ST2 promoter in mast cells/basophils: opposing roles for GATA2 and GATA1 in human IL1RL1/ST2 gene expression," Journal of Biological Chemistry, vol. 287, no. 39, pp. 32689-32696, 2012.

[35] C.-L. Hsu, C. V. Neilsen, and P. J. Bryce, "IL-33 is produced by mast cells and regulates IgE-dependent inflammation," PLoS ONE, vol. 5, no. 8, Article ID e11944, 2010.

[36] E. Schneider, A.-F. Petit-Bertron, R. Bricard et al., "IL-33 activates unprimed murine basophils directly in vitro and induces their in vivo expansion indirectly by promoting hematopoietic growth factor production," Journal of Immunology, vol. 183, no. 6, pp. 3591-3597, 2009.

[37] M. D. Smithgall, M. R. Comeau, B.-R. Park Yoon, D. Kaufman, R. Armitage, and D. E. Smith, "IL-33 amplifies both Th1- and Th2-type responses through its activity on human basophils, allergen-reactive Th 2 cells, iNKT and NK Cells," International Immunology, vol. 20, no. 8, pp. 1019-1030, 2008.

[38] M. Suzukawa, M. Iikura, R. Koketsu et al., "An IL-1 cytokine member, IL-33, induces human basophil activation via its ST2 receptor," Journal of Immunology, vol. 181, no. 9, pp. 5981-5989, 2008.

[39] W. V. Bonilla, A. Fröhlich, K. Senn et al., “The alarmin interleukin-33 drives protective antiviral CD8+ $\mathrm{T}$ cell responses," Science, vol. 335, no. 6071, pp. 984-989, 2012.

[40] L. Blom, B. C. Poulsen, B. M. Jensen, A. Hansen, and L. K. Poulsen, "IL-33 induces IL-9 production in human CD4+ T cells and basophils," PLoS ONE, vol. 6, no. 7, Article ID e21695, 2011.

[41] M. Milovanovic, V. Volarevic, G. Radosavljevic et al., "IL-33/ST2 axis in inflammation and immunopathology," Immunologic Research, vol. 52, no. 1-2, pp. 89-99, 2012.

[42] B. S. Kim, M. C. Siracusa, S. A. Saenz et al., "TSLP elicits IL33-independent innate lymphoid cell responses to promote skin inflammation," Science Translational Medicine, vol. 5, no. 170, Article ID 170ra16, 2013.

[43] S. Sattler, H. H. Smits, D. Xu, and F.-P. Huang, "The evolutionary role of the IL-33/ST2 system in host immune defence," Archivum Immunologiae et Therapiae Experimentalis, vol. 61, no. 2, pp. 107-117, 2013.

[44] M. Kurokawa, S. Matsukura, M. Kawaguchi et al., "Interleukin33-activated dendritic cells induce the production of thymus and activation-regulated chemokine and macrophage-derived chemokine," International Archives of Allergy and Immunology, vol. 161, supplement 2, pp. 52-57, 2013.

[45] Z. Su, J. Lin, F. Lu et al., "Potential autocrine regulation of interleukin-33/ST2 signaling of dendritic cells in allergic inflammation," Mucosal Immunology, vol. 6, no. 5, pp. 921-930, 2013.

[46] G. Palmer, D. Talabot-Ayer, C. Lamacchia et al., "Inhibition of interleukin-33 signaling attenuates the severity of experimental arthritis," Arthritis and Rheumatism, vol. 60, no. 3, pp. 738-749, 2009.
[47] K. Oboki, S. Nakae, K. Matsumoto, and H. Saito, "IL-33 and airway inflammation," Allergy, Asthma and Immunology Research, vol. 3, no. 2, pp. 81-88, 2011.

[48] R. Kakkar and R. T. Lee, “The IL-33/ST2 pathway: therapeutic target and novel biomarker," Nature Reviews Drug Discovery, vol. 7, no. 10, pp. 827-840, 2008.

[49] G. Haraldsen, J. Balogh, J. Pollheimer, J. Sponheim, and A. M. Küchler, "Interleukin-33-cytokine of dual function or novel alarmin?" Trends in Immunology, vol. 30, no. 5, pp. 227-233, 2009.

[50] A. A. Chackerian, E. R. Oldham, E. E. Murphy, J. Schmitz, S. Pflanz, and R. A. Kastelein, "IL-1 receptor accessory protein and ST2 comprise the IL-33 receptor complex," Journal of Immunology, vol. 179, no. 4, pp. 2551-2555, 2007.

[51] G. Palmer, B. P. Lipsky, M. D. Smithgall et al., “The IL-1 receptor accessory protein (AcP) is required for IL-33 signaling and soluble AcP enhances the ability of soluble ST2 to inhibit IL-33," Cytokine, vol. 42, no. 3, pp. 358-364, 2008.

[52] J. Hong, S. Bae, H. Jhun et al., "Identification of constitutively active interleukin 33 (IL-33) splice variant," Journal of Biological Chemistry, vol. 286, no. 22, pp. 20078-20086, 2011.

[53] R. Mu, H.-Q. Huang, Y.-H. Li, C. Li, H. Ye, and Z.-G. Li, "Elevated serum interleukin 33 is associated with autoantibody production in patients with rheumatoid arthritis," Journal of Rheumatology, vol. 37, no. 10, pp. 2006-2013, 2010.

[54] Y. Matsuyama, H. Okazaki, H. Tamemoto et al., "Increased levels of interleukin 33 in sera and synovial fluid from patients with active rheumatoid arthritis," Journal of Rheumatology, vol. 37, no. 1, pp. 18-25, 2010.

[55] P. Martin, D. Talabot-Ayer, C. A. Seemayer et al., "Disease severity in $\mathrm{K} / \mathrm{BxN}$ serum transfer-induced arthritis is not affected by IL-33 deficiency," Arthritis Research and Therapy, vol. 15, no. 1, article R13, 2013.

[56] I. A. Scarisbrick, R. Linbo, A. G. Vandell et al., "Kallikreins are associated with secondary progressive multiple sclerosis and promote neurodegeneration," Biological Chemistry, vol. 389, no. 6, pp. 739-745, 2008.

[57] W. J. Karpus, K. J. Kennedy, B. T. Fife et al., "Anti-CCL2 treatment inhibits Theiler's murine encephalomyelitis virusinduced demyelinating disease," Journal of NeuroVirology, vol. 12, no. 4, pp. 251-261, 2006.

[58] G. P. Christophi, R. C. Gruber, M. Panos, R. L. Christophi, B. Jubelt, and P. T. Massa, "Interleukin-33 upregulation in peripheral leukocytes and CNS of multiple sclerosis patients," Clinical Immunology, vol. 142, no. 3, pp. 308-319, 2012.

[59] S. Ali, A. Mohs, M. Thomas et al., "The dual function cytokine IL-33 interacts with the transcription factor NF- $\kappa$ B to dampen NF- $\kappa$ B-stimulated gene transcription," Journal of Immunology, vol. 187, no. 4, pp. 1609-1616, 2011.

[60] C. A. Hudson, G. P. Christophi, R. C. Gruber, J. R. Wilmore, D. A. Lawrence, and P. T. Massa, "Induction of IL-33 expression and activity in central nervous system glia (Journal of Leukocyte Biology (2008), 84)," Journal of Leukocyte Biology, vol. 89, no. 2, p. 319, 2011.

[61] M. Li, Y. Li, X. Liu, X. Gao, and Y. Wang, "IL-33 blockade suppresses the development of experimental autoimmune encephalomyelitis in C57BL/6 mice," Journal of Neuroimmunology, vol. 247, no. 1-2, pp. 25-31, 2012.

[62] H.-R. Jiang, M. Milovanović, D. Allan et al., "IL-33 attenuates EAE by suppressing IL-17 and IFN- $\gamma$ production and inducing alternatively activated macrophages," European Journal of Immunology, vol. 42, no. 7, pp. 1804-1814, 2012. 
[63] M. Milovanovic, V. Volarevic, B. Ljujic et al., "Deletion of IL33R (ST2) abrogates resistance to EAE in BALB/C mice by enhancing polarization of APC to inflammatory phenotype," PLoS ONE, vol. 7, no. 9, Article ID e45225, 2012.

[64] A. J. Mangini, R. Lafyatis, and J. M. van Seventer, “Type I interferons inhibition of inflammatory $\mathrm{T}$ helper cell responses in systemic lupus erythematosus," in Autoimmunity, Partt D: Autoimmune Disease, Annus Mirabilis, Y. Shoenfeld and M. E. Gershwin, Eds., pp. 11-23, 2007.

[65] K. Kuroiwa, T. Arai, H. Okazaki, S. Minota, and S.-I. Tominaga, "Identification of human ST2 protein in the sera of patients with autoimmune diseases," Biochemical and Biophysical Research Communications, vol. 284, no. 5, pp. 1104-1108, 2001.

[66] M. Y. Mok, F. P. Huang, W. K. Ip et al., "Serum levels of IL-33 and soluble ST2 and their association with disease activity in systemic lupus erythematosus," Rheumatology, vol. 49, no. 3, pp. 520-527, 2009.

[67] C. J. Beltrán, L. E. Núñez, D. Díaz-Jiménez et al., "Characterization of the novel ST2/IL-33 system in patients with inflammatory bowel disease," Inflammatory Bowel Diseases, vol. 16, no. 7, pp. 1097-1107, 2010.

[68] A. Kobori, Y. Yagi, H. Imaeda et al., "Interleukin-33 expression is specifically enhanced in inflamed mucosa of ulcerative colitis," Journal of Gastroenterology, vol. 45, no. 10, pp. 999-1007, 2010.

[69] L. Pastorelli, R. R. Garg, S. B. Hoang et al., "Epithelial-derived IL-33 and its receptor ST2 are dysregulated in ulcerative colitis and in experimental Th1/Th2 driven enteritis," Proceedings of the National Academy of Sciences of the United States of America, vol. 107, no. 17, pp. 8017-8022, 2010.

[70] J. B. Seidelin, J. T. Bjerrum, M. Coskun, B. Widjaya, B. Vainer, and O. H. Nielsen, "IL-33 is upregulated in colonocytes of ulcerative colitis," Immunology Letters, vol. 128, no. 1, pp. 80-85, 2010.

[71] G. Bamias, C. Martin III, M. Mishina et al., "Proinflammatory effects of TH2 cytokines in a murine model of chronic small intestinal inflammation," Gastroenterology, vol. 128, no. 3, pp. 654-666, 2005.

[72] C. Garlanda, H.-J. Anders, and A. Mantovani, "TIR8/SIGIRR: an IL-1R/TLR family member with regulatory functions in inflammation and T cell polarization," Trends in Immunology, vol. 30, no. 9, pp. 439-446, 2009.

[73] H. Hammad, M. Chieppa, F. Perros, M. A. Willart, R. N. Germain, and B. N. Lambrecht, "House dust mite allergen induces asthma via Toll-like receptor 4 triggering of airway structural cells," Nature Medicine, vol. 15, no. 4, pp. 410-416, 2009.

[74] K. Bulek, S. Swaidani, J. Z. Qin et al., “The essential role of single Ig IL-1 receptor-related molecule/Toll IL-1R8 in regulation of Th2 immune response," Journal of Immunology, vol. 182, no. 5, pp. 2601-2609, 2009.

[75] C. Garlanda, F. Riva, N. Polentarutti et al., "Intestinal inflammation in mice deficient in Tir8, an inhibitory member of the IL-1 receptor family," Proceedings of the National Academy of Sciences of the United States of America, vol. 101, no. 10, pp. 3522-3526, 2004.

[76] M. Milovanovic, V. Volarevic, G. Radosavljevic et al., "IL-33/ST2 axis in inflammation and immunopathology," Immunologic Research, vol. 52, no. 1-2, pp. 89-99, 2012.

[77] Y. Kageyama, E. Torikai, K. Tsujimura, and M. Kobayashi, "Involvement of IL-33 in the pathogenesis of rheumatoid arthritis: the effect of etanercept on the serum levels of IL-33," Modern Rheumatology, vol. 22, no. 1, pp. 89-93, 2012.
[78] H. E. Barksby, S. R. Lea, P. M. Preshaw, and J. J. Taylor, “The expanding family of interleukin-1 cytokines and their role in destructive inflammatory disorders," Clinical and Experimental Immunology, vol. 149, no. 2, pp. 217-225, 2007.

[79] B. P. Leung, D. Xu, S. Culshaw, I. B. McInnes, and F. Y. Liew, "A novel therapy of murine collagen-induced arthritis with soluble T1/ST2," Journal of Immunology, vol. 173, no. 1, pp. 145-150, 2004.

[80] A. Lingel, T. M. Weiss, M. Niebuhr et al., "Structure of IL-33 and its interaction with the ST2 and IL-1RAcP receptors-insight into heterotrimeric IL-1 signaling complexes," Structure, vol. 17, no. 10, pp. 1398-1410, 2009.

[81] S. Sanada, D. Hakuno, L. J. Higgins, E. R. Schreiter, A. N. J. McKenzie, and R. T. Lee, "IL-33 and ST2 comprise a critical biomechanically induced and cardioprotective signaling system," Journal of Clinical Investigation, vol. 117, no. 6, pp. 15381549, 2007.

[82] D. Xu, H.-R. Jiang, P. Kewin et al., "IL-33 exacerbates antigeninduced arthritis by activating mast cells," Proceedings of the National Academy of Sciences of the United States of America, vol. 105, no. 31, pp. 10913-10918, 2008.

[83] D. Talabot-Ayer, T. McKee, P. Gindre et al., "Distinct serum and synovial fluid interleukin (IL)-33 levels in rheumatoid arthritis, psoriatic arthritis and osteoarthritis," Joint Bone Spine, vol. 79, no. 1, pp. 32-37, 2012.

[84] W. A. Verri Jr., F. O. Souto, S. M. Vieira et al., "IL-33 induces neutrophil migration in rheumatoid arthritis and is a target of anti-TNF therapy," Annals of the Rheumatic Diseases, vol. 69, no. 9, pp. 1697-1703, 2010.

[85] A. M. Miller, D. Xu, D. L. Asquith et al., "IL-33 reduces the development of atherosclerosis," Journal of Experimental Medicine, vol. 205, no. 2, pp. 339-346, 2008.

[86] R. Andre, D. Lerouet, I. Kimber, E. Pinteaux, and N. J. Rothwell, "Regulation of expression of the novel IL-1 receptor family members in the mouse brain," Journal of Neurochemistry, vol. 95, no. 2, pp. 324-330, 2005.

[87] S. Yasuoka, J. Kawanokuchi, B. Parajuli et al., "Production and functions of IL-33 in the central nervous system," Brain Research, vol. 1385, pp. 8-17, 2011.

[88] C. A. Hudson, G. P. Christophi, R. C. Gruber, J. R. Wilmore, D. A. Lawrence, and P. T. Massa, "Induction of IL-33 expression and activity in central nervous system glia," Journal of Leukocyte Biology, vol. 84, no. 3, pp. 631-643, 2008.

[89] B. Kornek and H. Lassmann, "Neuropathology of multiple sclerosis-new concepts," Brain Research Bulletin, vol. 61, no. 3, pp. 321-326, 2003.

[90] G. P. Christophi, C. A. Hudson, M. Panos, R. C. Gruber, and P. T. Massa, "Modulation of macrophage infiltration and inflammatory activity by the phosphatase SHP-1 in virusinduced demyelinating disease," Journal of Virology, vol. 83, no. 2, pp. 522-539, 2009.

[91] L. Zhang, R. Lu, G. Zhao, S. C. Pflugfelder, and D.-Q. Li, “TLRmediated induction of pro-allergic cytokine IL-33 in ocular mucosal epithelium," International Journal of Biochemistry and Cell Biology, vol. 43, no. 9, pp. 1383-1391, 2011.

[92] M. Lamkanfi and V. M. Dixit, "Modulation of inflammasome pathways by bacterial and viral pathogens," Journal of Immunology, vol. 187, no. 2, pp. 596-602, 2011.

[93] Z. Yang, Y. Liang, W. Xi, C. Li, and R. Zhong, "Association of increased serum IL-33 levels with clinical and laboratory characteristics of systemic lupus erythematosus in Chinese 
population," Clinical and Experimental Medicine, vol. 11, no. 2, pp. 75-80, 2011.

[94] M. Lech, O. P. Kulkarni, S. Pfeiffer et al., “Tir8/Sigirr prevents murine lupus by suppressing the immunostimulatory effects of lupus autoantigens," Journal of Experimental Medicine, vol. 205, no. 8, pp. 1879-1888, 2008.

[95] D. Díaz-Jiménez, L. E. Núñez, C. J. Beltrán et al., "Soluble ST2: a new and promising activity marker in ulcerative colitis," World Journal of Gastroenterology, vol. 17, no. 17, pp. 2181-2190, 2011.

[96] L. Pastorelli, C. de Salvo, M. Vecchi, and T. T. GvPizarro, "The role of IL-33 in gut mucosal inflammation," Mediators of Inflammation, vol. 2013, Article ID 608187, 11 pages, 2013.

[97] M. A. K. Sedhom, M. Pichery, J. R. Murdoch et al., "Neutralisation of the interleukin-33/ST2 pathway ameliorates experimental colitis through enhancement of mucosal healing in mice," Gut, vol. 62, pp. 1714-1723, 2013.

[98] P. Groß, K. Doser, W. Falk, F. Obermeier, and C. Hofmann, "IL-33 attenuates development and perpetuation of chronic intestinal inflammation," Inflammatory Bowel Diseases, vol. 18, no. 10, pp. 1900-1909, 2012.

[99] P. N. Pushparaj, D. Li, M. Komai-Koma et al., "Interleukin-33 exacerbates acute colitis via interleukin-4 in mice," Immunology, vol. 140, no. 1, pp. 70-77, 2013.

[100] A. Latiano, O. Palmieri, L. Pastorelli et al., "Associations between genetic polymorphisms in IL-33, IL1R1 and risk for inflammatory bowel disease," PLoS ONE, vol. 8, no. 4, Article ID e62144, 2013.

[101] G. E. J. Murphy, D. Xu, F. Y. Liew, and I. B. McInnes, "Role of interleukin 33 in human immunopathology," Annals of the Rheumatic Diseases, vol. 69, no. 1, pp. i43-i47, 2010. 


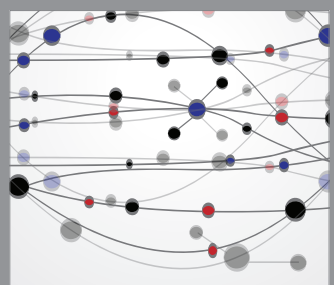

The Scientific World Journal
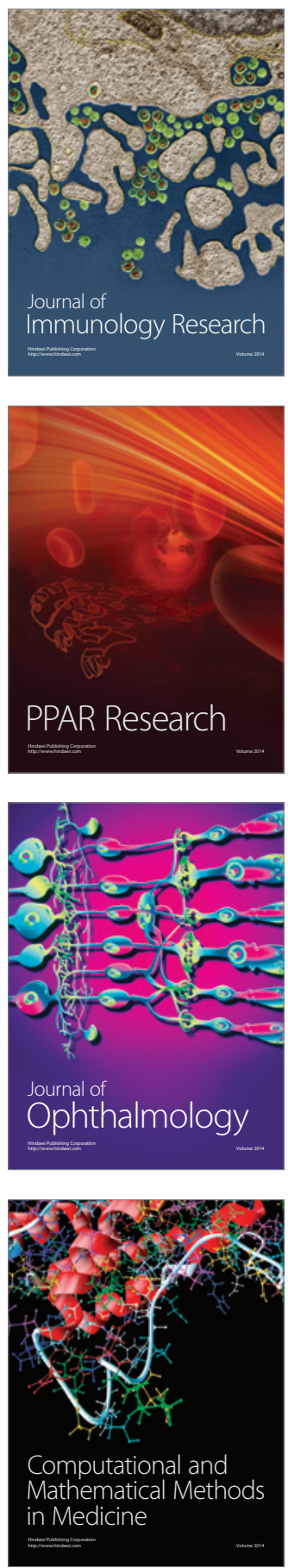

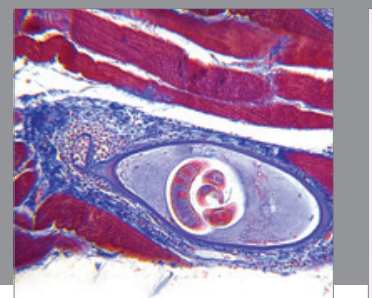

Gastroenterology

Research and Practice
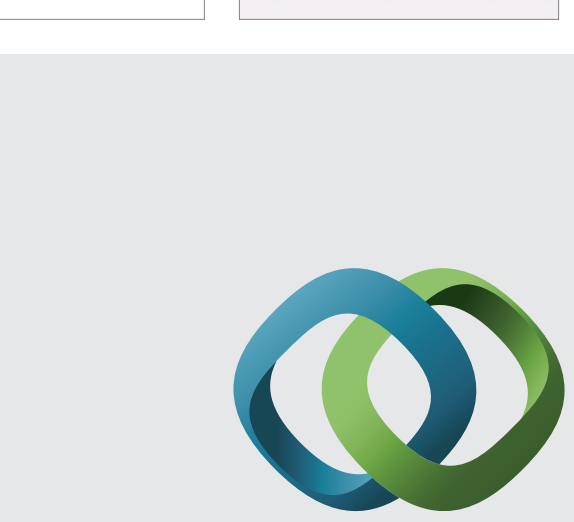

\section{Hindawi}

Submit your manuscripts at

http://www.hindawi.com
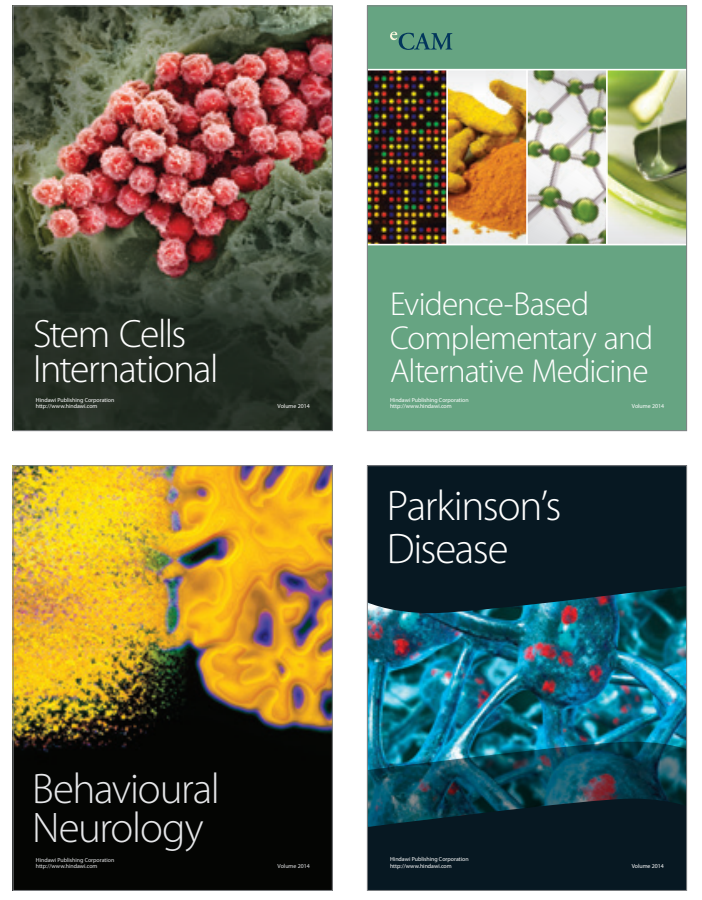
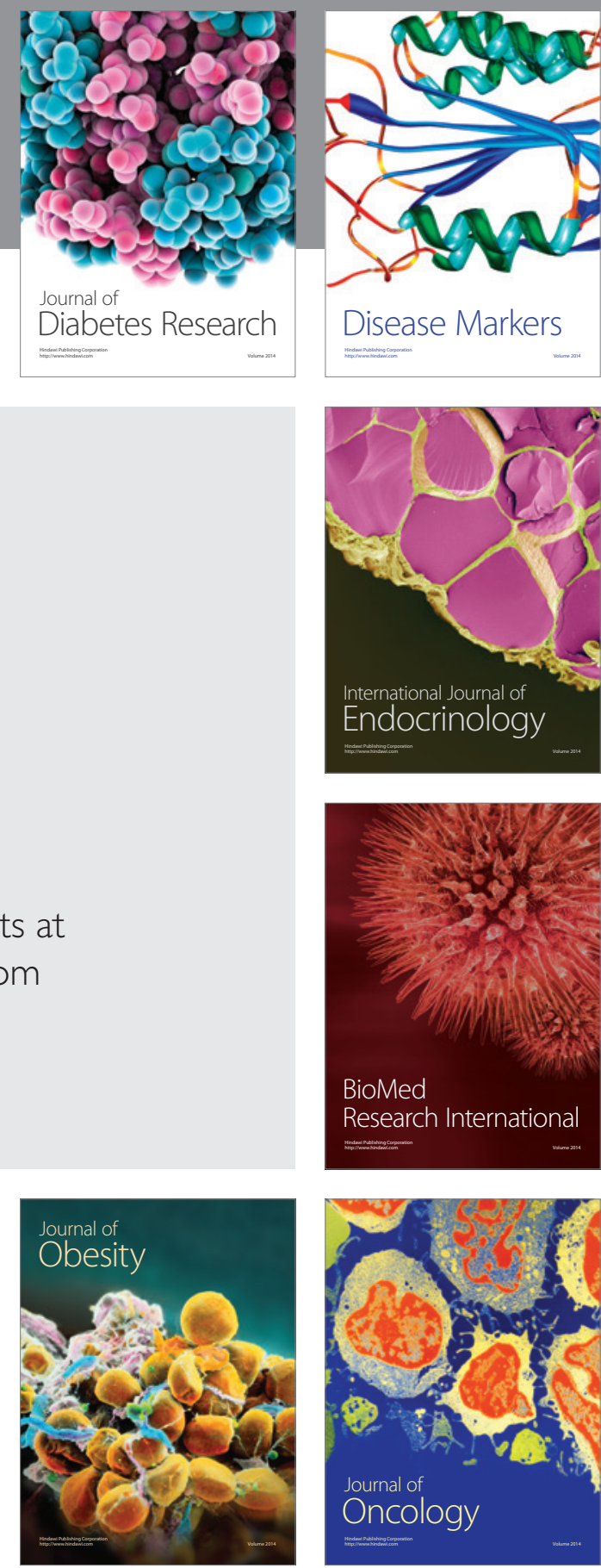

Disease Markers
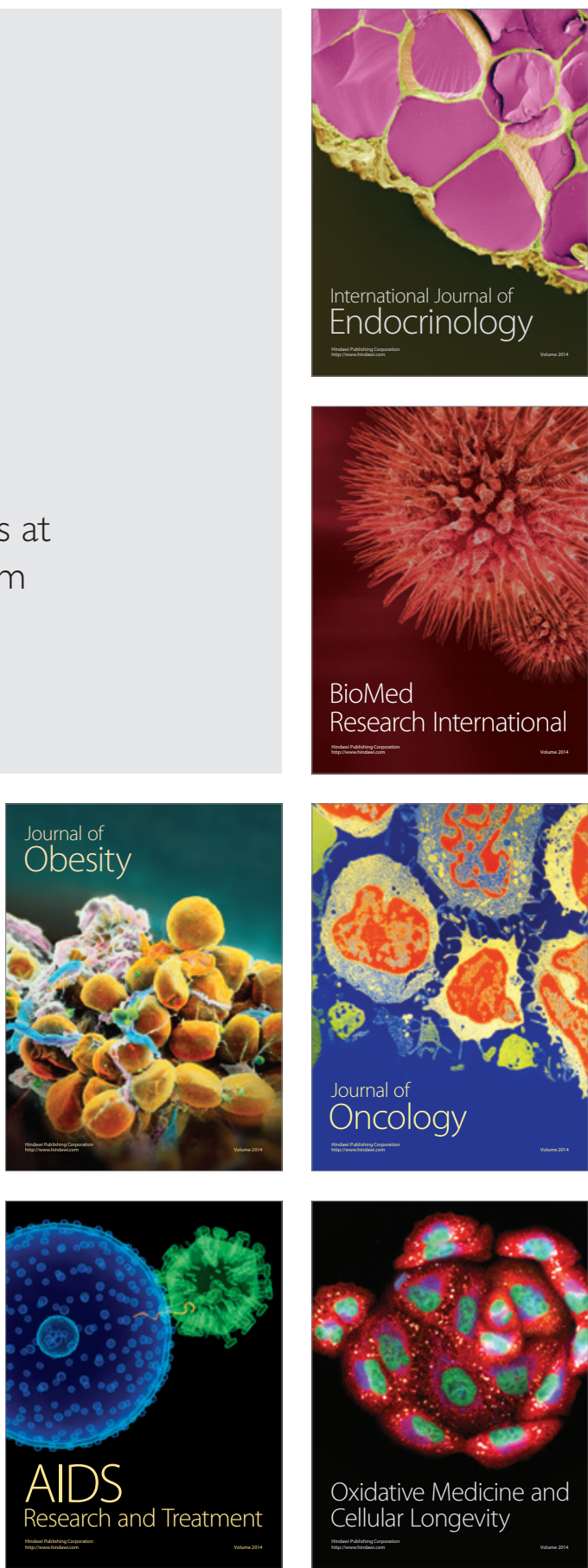